\title{
Políticas de empleo con enfoque de género: formación laboral en oficios no tradicionales para mujeres*
}

Verónica Millenaar**

\section{Resumen}

El artículo analiza, desde una perspectiva de género, un programa de formación profesional en oficios no tradicionales para mujeres, desarrollado por el Ministerio de Trabajo de la Argentina durante los años 2012 y 2013. Dicho programa es paradigmático por múltiples razones: se trata del fruto de una articulación público/privada; busca ofrecer un tipo de formación técnica para mujeres de sectores populares basada en criterios de detección de oferta de empleo; incorpora una perspectiva de género, ofreciendo una estrategia que se auto-nomina "rupturista". A través de entrevistas en profundidad con referentes del programa, docentes y alumnos/as, el artículo tiene el objetivo de analizar y proponer reflexiones críticas en torno a las diferentes concepciones de género disputadas durante el complejo proceso de implementación del programa que generó tensiones, obstáculos y desafíos.

Palabras clave: Formación Profesional, Políticas de Empleo, Género, Socialización Laboral, Mercado de Trabajo.

* Recibido en 31 de octubre de 2015, aceptado en 28 de marzo de 2017.

** Investigadora posdoctoral del PREJET-CIS-IDES/CONICET, Ciudad de Buenos Aires, Argentina. veronicamillenaar@gmail.com 
Employment Policies with a Gender Perspective: Vocational Training in Non-Traditional Jobs for Women

\begin{abstract}
The article analyzes, from a gender perspective, a program based on the offer of vocational training in non-traditional occupations for women, developed by the Ministry of labour Argentina during the years 2012 and 2013. This is a paradigmatic program for many reasons: it is the fruit of a public/private joint; seeks to offer a type of technical and vocational training to women that belong to low social backgrounds based on the criteria of the supply side of the labour maket; incorporates a gender perspective, offering a "disruptive" strategy. Through in-depth interviews with different actors (references from the program, teachers and students), the article aims to analyze and contribute with critical reflections around the different conceptions of gender, disputed during the complex process of implementation of the program that generated tensions, obstacles and challenges.
\end{abstract}

Keywords: Vocational Training, Employment Policies, Gender, Occupational Socialization, Labour Market. 


\section{Introducción}

El mercado de trabajo es un espacio social que evidencia de forma clara y medible una "gramática de género" (Faur y Zamberlin, 2008; Segato, 2003). Los estudios de género que se ocupan del análisis del mercado de empleo en Argentina y otros contextos, aportan elementos relevantes sobre la desigualdad derivada de la división sexual del trabajo (OIT, 2013; CEMyT, 2011; Novick, Rojo y Castillo, 2008, Rojo y Tumini, 2008) y que se plasma en la segmentación horizontal y vertical, las brechas salariales y otros tipos de discriminación (encubiertas, auto-discriminación, "techos y paredes de cristal") (Yannoulas, 2013).

Una lectura de trayectorias laborales de varones y mujeres desde esta perspectiva se esfuerza por hacer visible el modo en que se organizan "caminos" diferentes en la inserción ocupacional -a través de mandatos, expectativas sociales, habilitaciones y restricciones específicas-, que lleva a varones y mujeres (aunque no siempre del mismo modo) a otorgar sentidos y apropiarse del trabajo en sus particulares recorridos biográficos. En este sentido, las desigualdades de género en el mercado de trabajo no sólo se explican por las oportunidades laborales (caracterizadas por la segregación de género que las atraviesa), sino también por la disponibilidad subjetiva a emplearse en determinadas actividades laborales y en diferentes condiciones, de acuerdo al género. La gramática de género incide en varones y mujeres orientando prácticas, decisiones y también afecciones que se despliegan en torno a la vida laboral.

Así, en la comprensión de las trayectorias laborales, cobran relevancia las instancias de formación laboral y acercamiento al empleo, en tanto se vuelven mecanismos clave en el modo en que se construyen identidades, sentidos sobre el trabajo y proyectos laborales. Sobre todo en Inglaterra, algunos estudios de referencia en esta materia han señalado, ya hace algunos años, que la formación laboral tiene un relevante papel en la socialización ocupacional, de género y de clase, en tanto la misma se evidencia como dispositivo de disciplinamiento y de construcción social de 
habilidades en relación al mercado de trabajo (Skeggs, 1997; Bates, 1991).

En Argentina, la incidencia de la Formación Profesional $(\mathrm{FP})^{1}$ en las trayectorias laborales se ha vuelto un interrogante de importancia en años recientes (Jacinto y Millenaar, 2013; Jacinto y Gallart, 1998). Se ha indagado en torno a su rol, mostrando que, a pesar de la heterogeneidad que la caracteriza, su contribución es significativa en el mejoramiento de oportunidades de empleo, principalmente para jóvenes de bajos recursos, como así también en la socialización laboral, la profesionalización y la ampliación de saberes. Sin embargo, también se constatan diferencias en las trayectorias de varones y mujeres que participan de experiencias de FP, en tanto los varones suelen tener mejores inserciones luego de su egreso (Millenaar y Jacinto, 2015). Por un lado, si se comparan en términos objetivos las trayectorias de mujeres y varones luego de la formación, se observa que ellos, en mayor medida que las mujeres, evidencian una movilidad hacia la formalidad, inserción en establecimientos de mayor tamaño, ocupaciones de mayor calificación y reducción de la sub-ocupación horaria. Por otro lado, se observa que los mismos centros de FP reproducen desigualdades de género en la oferta de sus cursos, segmentada de acuerdo a la división sexual del trabajo. Mujeres y varones se vinculan a dos tipos de cursos de FP: aquellos típicamente masculinos y aquellos típicamente femeninos, orientados a empleos de diferente calidad. La oferta orientada a los varones se encuentra vinculada a empleos en el sector formal y con mejores

${ }^{1}$ La oferta de FP en la Argentina es amplia y heterogénea. Comprende cursos de formación en oficios y tareas laborales, de duración variable, que puede extenderse desde cuatro meses hasta los dos años. Los cursos se ofrecen desde distintos centros estatales o conveniados con entidades sindicales o sociales, vinculados a los Ministerios de Educación y/o de Trabajo, quienes extienden una titulación oficial. Generalmente se exige, para su ingreso, el título de primaria completa. En este sentido, es una oferta formativa considerada, histórica, y colectivamente, como un camino alternativo al nivel secundario (aunque esto ha ido cambiando en los últimos tiempos), que se orienta hacia la inserción laboral. La edad mínima de ingreso son los 16 años, siguiendo la normativa vigente en relación a la edad requerida para comenzar a trabajar. 
salarios, a diferencia de la oferta formativa dirigida a las mujeres (Millenaar y Jacinto, 2015). Generalmente la FP orienta su formación de acuerdo a una determinada socialización de género patriarcal y jerarquizada, haciéndose esto más evidente en los estratos más pobres y menos escolarizados.

Estas evidencias se suman a los diferentes sentidos y expectativas que manifiestan varones y mujeres respecto de estos cursos. Desde estudios sobre trayectorias laborales centrados en aspectos subjetivos, hemos mostrado que los y las cursantes que se acercan a los centros de FP aspiran a encontrar allí experiencias y recursos que varían significativamente según el género, como así también de acuerdo a sus edades, capital educativo, lugar de residencia, si cuentan o no con experiencia laboral. Estas demandas suponen desafíos contrastantes para las instituciones. Por ejemplo, en el caso de las mujeres jóvenes en particular, el acercamiento a los cursos de FP se da a partir de tan diferentes intereses como el de adquirir una certificación, profesionalizarse, encontrar un espacio de sociabilidad, aprender una nueva actividad o "testear" una vocación no del todo definida (Millenaar, 2014).

Por lo tanto, cuando se estudia la incidencia de la FP en las trayectorias laborales, surge como elemento clave del análisis la perspectiva de género con la que se desarrolla la intervención institucional. El modo en que los dispositivos de FP conciben la problemática de género tiene consecuencias en el ofrecimiento de sus cursos, sus diseños curriculares, los contenidos que se enseñan y el tratamiento que se les da a varones y mujeres. En general, las investigaciones han mostrado que los espacios educativos promueven acríticamente en sus visiones y prácticas la reproducción de las desigualdades de género (Morgade y Kaplan, 1999; Subirats, 1999). Esto se observa en general para la escuela secundaria, y en particular para la escuela técnica, en la cual abundan los registros de subestimación y desvalorización de docentes y directores sobre las alumnas mujeres que se manifiestan en las prácticas educativas: en muchos casos, a las 
chicas se les prohíbe manipular máquinas o se les asignan tareas diferentes por el mero hecho de ser mujeres (León, 2009).

Así, puede sostenerse que el rol de la FP se vincula al proceso imbricado de conformación de una subjetividad ligada al trabajo, y de despliegue de estrategias de disciplinamiento laboral (Skeggs, 1997). Los dispositivos de FP producen diferentes modos de subjetivación, que se vinculan, como hemos visto, a la división sexual del trabajo, como así también a las lógicas de formación requeridas por el capitalismo contemporáneo (Figari, Spinosa y Testa, 2011). En este marco, generalmente, las mujeres son formadas para ocupar puestos vinculados al mundo doméstico y a las tareas de cuidado. Esta segmentación laboral está acompañada por distintas valoraciones sociales de uno y otros empleos, como así también por su distinta jerarquización en materia de remuneración.

En este marco, una política de empleo orientada a revertir dicha segmentación, debería poder producir un corrimiento de la inserción laboral de las mujeres hacia nichos ocupacionales que socialmente están asignados a los varones. Este objetivo podría desarrollarse desde una intervención explicita en función de la reasignación de puestos laborales para mujeres y varones, como así también desde una estrategia de promoción de carreras profesionales más equitativas, a partir de garantizar las mismas oportunidades de formación en varones y mujeres.

La elección del caso de estudio que aquí se presenta adquiere relevancia ${ }^{2}$ pues se trata de un programa de formación

2 Cabe señalar que, desde los años 80 , comenzó a promoverse a nivel latinoamericano la inclusión de enfoques de género en las políticas dirigidas a promover la inclusión laboral (Silveira, 2001). Particularmente en el caso de la $\mathrm{FP}$, se reconocen antecedentes de incorporación de estos contenidos de género (Maurizio, 2010; Yannoulas, 2005; FORMUJER, 2004), que apuntaron a promover, principalmente, la visualización de los propios derechos laborales entre las mujeres. Sin embargo, en la actualidad, aunque con diferencias y matices, la oferta de capacitación laboral prácticamente no incorpora ningún tipo de componente de género de modo explícito y suele primar una oferta de formación tradicional y diferenciada para mujeres y varones, como un reflejo directo de la lógica de la segmentación laboral. 
que incorpora un enfoque de género de modo explícito. Observar tanto su diseño como su proceso de implementación apunta a recuperar una experiencia novedosa que, aunque se desarrolle en forma aislada, lleva a interrogarse sobre sus posibilidades efectivas de producir nuevos modos de socialización laboral y de género. Si bien este trabajo no tiene intenciones de realizar una evaluación del programa, sí busca analizar críticamente sus acciones basándose en un trabajo empírico. El fin de este ejercicio es el de contribuir a la reflexión teórica en torno a los procesos de subjetivación y concientización de la desigualdad de género que permiten ampliar las oportunidades laborales de mujeres y disminuir las brechas existentes con sus pares varones. En este sentido, situamos nuestro interés en comprender, en el actual contexto de la Argentina, qué implicancias tiene desarrollar una política de FP "con enfoque de género". ¿A qué componentes, acciones o propuestas remite dicho "enfoque"? ¿A partir de qué perspectivas y fundamentos se lo diseña, y a qué diagnósticos sobre la desigualdad laboral entre varones y mujeres intenta responder? ¿Qué posibilidades y que obstáculos se evidencian en el momento de llevarlo a la práctica? ¿Cómo es recibido por los actores involucrados en el desarrollo de tal política?

Como podrá verse en el trabajo, desde el momento del diseño del programa, pero sobre todo en el proceso de su implementación, se desplegaron intensas disputas entre los diferentes actores involucrados en la política produciendo una puesta en marcha de las acciones cargada de tensiones y conflictos. Como se verá, el presente estudio muestra que la incorporación de un "enfoque de género" en este tipo de intervenciones, en definitiva, moviliza concepciones más amplias en torno a la justicia y los derechos para mujeres y varones.

En este sentido, un aporte a estas reflexiones se reconoce en el trabajo de Dubet (2011) que postula que toda política pública es derivada de concepciones diferentes en torno a la justicia. Por un lado, una primera concepción, aboga por la redistribución social (igualdad de posiciones), basándose en el supuesto de que para alcanzar la justicia social debe buscarse reducir las diferencias 
existentes en la población, acercando entre sí a personas que ocupan lugares diferentes en la estructura social. Esta posición plantea que las inequidades pueden reducirse si el Estado media regulando y enmarcando el funcionamiento capitalista, y particularmente del mercado de trabajo. Por otro lado, una segunda concepción promueve la agencia personal (igualdad de oportunidades) y procura ofrecer las mismas condiciones de partida. Si las personas tienen las mismas posibilidades, a partir del principio meritocrático todas ellas podrán acceder a las posiciones más jerarquizadas. Argumentamos que estas concepciones pueden complejizarse desde una perspectiva de la inclusión y la justicia social en clave de género, y para ello resultan centrales los aportes de Nancy Fraser (1997, 2008). Esta autora muestra como las concepciones de las políticas no sólo pueden estar orientadas hacia procesos redistributivos (cuando se enfatizan en las injusticias económicas), sino también al reconocimiento de las identidades (cuando se enfatizan en las injusticias a nivel de las discriminaciones culturales) y a la representación (cuando se enfatizan en las injusticias de falta de representación y/o participación política). Ella plantea que la desigualdad de género conlleva injusticias en todos estos terrenos (de la redistribución, del reconocimiento y de la representación) que plantea mayores desafíos a la intervención de las políticas. La concepción compleja del género que aporta Fraser no siempre se pone en consideración cuando se diseñan políticas con enfoque de género, cuestión que ha sido fuente de tensiones en el caso del programa de FP estudiado.

Metodológicamente, el presente trabajo resulta de un estudio cualitativo ${ }^{3}$, que se basa en las visiones, voces y reflexiones, tanto de los actores institucionales implicados en esta

${ }^{3}$ Este caso de estudio forma parte de mi tesis doctoral titulada: "Trayectorias educativo-laborales de varones y mujeres jóvenes de sectores populares que participan de dispositivos de formación para el trabajo (Área Metropolitana de Buenos Aires, 2008-2014). Entre la profesionalización, la activación y la socialización", dirigida por la Dra. Claudia Jacinto en el marco de Programa de Estudios sobre Juventud, Educación y Trabajo (PREJET-CIS-IDES/CONICET). 
experiencia, como de egresados y egresadas. Los datos en los cuales se basa el trabajo se recolectaron a lo largo del trabajo de campo en uno de los centros donde se desarrolló el programa, en el cual pudieron recolectarse: 1) fuentes secundarias (el diseño formal del programa, evaluaciones y videos institucionales), 2) observaciones no participantes de clases y presentaciones institucionales y 3) 19 entrevistas en profundidad (realizadas en distintos momentos entre 2013 y 2014) a la funcionaria y equipo técnico implicados, director de la confederación empresarial, instructor y formadora en género, como así también a 5 egresadas mujeres y 10 egresados varones. Todas las entrevistas y observaciones fueron registradas y transcritas, para luego ser procesadas con la ayuda del software ATLAS Ti. La estrategia de análisis se ha basado en el enfoque interpretativo, que busca comprender analíticamente el esfuerzo del programa a partir de la visión de los diferentes actores y de una reflexión crítica y en diálogo con lecturas desde la teoría de género, que discuten los desafíos pendientes de las políticas públicas, en relación a la igualación de oportunidades laborales de mujeres y varones.

El trabajo a continuación, se estructura de la siguiente manera. En primer lugar, se ofrece una descripción de las características del programa mencionado, de su alcance, componente y acciones. En segundo lugar analizaremos, contrastando las voces de los/as diferentes entrevistados/as, la filosofía de género del programa, que si bien se explicita en su diseño, se reinterpreta de múltiples maneras a lo largo de su implementación. En tercer lugar analizaremos el desarrollo mismo de la política, mostrando las dificultades y resistencias con las que debió enfrentarse, reflexionando sobre el carácter complejo de una intervención basada en un enfoque de género rupturista, que se propone cuestionar la división sexual del trabajo. 


\section{Formar a las mujeres en oficios no tradicionales: caracterización del programa y filosofía de género}

El Ministerio de Trabajo, a través de una de sus áreas de coordinación de políticas de género, implementó, a partir de 2012, un proyecto de formación en oficios no tradicionales para las mujeres, en forma conjunta con un área de formación continua, y una confederación empresarial, que fue el organismo ejecutor del proyecto. Las acciones se inician cuando en octubre de 2011 se firma un convenio marco entre la Secretaría de Empleo y la confederación empresarial, que pone en marcha el programa sectorial de capacitación, que aspira a brindar cursos de mecánica de moto vehículos básica y avanzada, electricidad, servicio técnico y mantenimiento de motos, motores a explosión de 2 y 4 tiempos y mecánica ligera conjunta. Este Programa se articula, en su formulación, con las acciones que venía desarrollando la Coordinación de género de ese ministerio, a través de un programa de promoción de nuevos oficios para las mujeres. En este sentido, el programa de formación involucraba el convenio entre dos áreas del Ministerio de Trabajo, una confederación de cámaras empresarias y empresas vinculadas a la industria de motos.

La perspectiva de género del programa establecía, principalmente, la promoción de la formación laboral entre las mujeres, estableciendo un cupo de un $40 \%$ en la inscripción para ellas. Asimismo, se incluían talleres de sensibilización en temáticas de género, tanto para las cursantes mujeres como para los instructores (todos varones, en la medida en que se trata de una ocupación vinculada al mundo masculino). El objetivo de priorizar una perspectiva de género radicaba en el diagnóstico que se hacía del sector, que se considera en crecimiento; así como del déficit que se visualizaba en la formación de recursos humanos, principalmente para ocupar las áreas de ventas de repuestos, mantenimiento y ensamble de motos. En conversaciones con la confederación empresarial, se asumía que estos oficios, a mediano plazo, tendrían que ser cubiertos por trabajadores calificados, no 
necesariamente varones. De todos modos, el diseño mismo del programa implicó una etapa previa de convencimiento al interior del sector, y de comprensión del objetivo al que se aspiraba.

\begin{abstract}
El Ministerio nos propuso incorporar el género y trabajarlo como un nuevo oficio para mujeres y nos pareció brillante. Porque si hay un estereotipo de hombre, de un oficio masculino, es el de mecánico (...)

¿El sector lo vio bien?

El sector lo vio bien, pero tuvimos que romper con todo. Mi primer coordinador técnico, que viene de una firma importante de motos, es una persona que sabe mucho y que dice "las mujeres para esto no sirven". Entonces tuve que trabajar con él y ahora entendió que sirven. (Director, confederación empresarial).
\end{abstract}

El área de género del Ministerio, ubicó sus propios objetivos en el programa, vinculados a la formación y participación de las mujeres. Desde una propuesta de política afirmativa, se buscó promover la incorporación de mujeres a una formación no tradicional para ellas. Asimismo, a partir de talleres en sensibilización de género, se propuso generar en las participantes mujeres $e$ instructores, cuestionamientos y revisiones de los estereotipos de género, vinculados a la división sexual de trabajo. De este modo, la filosofía de género detrás del programa apuntaba a revertir la segmentación horizontal del mercado de trabajo: desde una estrategia basada en la redistribución afirmativa -en términos de Nancy Fraser (1997)- la propuesta apuntaba a revertir la discriminación hacia las mujeres para el acceso a oportunidades de empleo en una rama de actividad en donde se evidencia mayor demanda laboral y mejor calidad del empleo. En este sentido, la propuesta se orientó a apuntalar a las mujeres para que ocupen esos espacios y revisar estereotipos de género que obstaculizan esa posibilidad.

¿La idea atrás de esto cuál es? Que socialmente no se visualiza a las mujeres, ni ellas mismas se visualizan, 
haciendo este tipo de formación, ni este tipo de trabajo. Por cuestiones culturales, se establece que hay determinados oficios que son propios de los varones y propios de las mujeres. Este programa se propone romper esta lógica de oficios de los varones. Por eso decimos que es un programa rupturista en términos culturales (...) Apuntamos a la igualdad, porque la mujer puede ocupar también esos espacios, y de esa manera se puede romper con la segmentación horizontal del mercado de trabajo. Pero para lograr eso tenés que garantizar un cupo. (Directora, Coordinación de género del Ministerio).

El Programa comenzó a funcionar en 2012 en cinco sedes en el país bajo la ejecución de la confederación empresarial: Caseros, Florencio Varela y Ciudad de Buenos Aires (Provincia de Buenos Aires), Ciudad de Salta (Provincia de Salta) y Villa María (Provincia de Córdoba). La propuesta se centró en el ofrecimiento del primer curso de mecánica básica, de 120 horas, que luego se continuó con el segundo nivel (mecánica avanzada), y con la realización de un taller de empleo independiente, que depende de otro programa que ofrece el Ministerio de Trabajo, a partir del cual se pueden otorgar subsidios para la compra de herramientas y se promueve el desarrollo de microemprendimientos.

La convocatoria a las participantes quedó en manos de las oficinas de empleo locales del Ministerio de Trabajo, que funcionan en las diferentes localidades en donde se ofrecían los cursos. Muchas de las participantes convocadas fueron beneficiarias de programas de promoción del empleo dirigidos a personas desocupadas, principalmente jóvenes. Por esta razón, una parte importante de la matrícula femenina estuvo compuesta por mujeres jóvenes desocupadas o con trabajos temporarios y no registrados. En la convocatoria se apuntó a explicitar el contenido del curso y lo que implica la decisión de iniciarlo: los afiches que lo publicitaban, interpelaban a "mujeres emprendedoras". Las chicas participantes de los cursos, durante las entrevistas, reflexionaron sobre esa convocatoria, asumiendo que se vieron motivadas por el desafío que implicaba "animarse a hacer algo distinto". Lo cierto 
es que, en muchos casos, se trató de mujeres con algún vínculo directo o indirecto con la mecánica o las motos específicamente a través de algún familiar.

\begin{abstract}
Era para mujeres emprendedoras, algo así; y a mí me gusta meterme en esas cosas raras. (Egresada, 24 años)

Yo de mecánica sé porque vengo de familia. Mi viejo laburó toda la vida en esto, hay una historia. (Egresada, 20 años)
\end{abstract}

Los talleres en sensibilización de género se pensaron con el objetivo de fortalecer a las mujeres desde el punto de vista individual y grupal, y con el fin de que adquieran herramientas para sostenerse en una capacitación típicamente masculina. Se pensó en un diseño de tres talleres (al comienzo, promediando y al finalizar el primer curso) para incorporar contenidos en relación al género: su conceptualización como construcción histórica y social, el lugar del trabajo productivo y reproductivo, la desigualdad entre varones y mujeres y los derechos laborales. Uno de los temas relevantes fue la revalorización del trabajo en la vida de las mujeres.

Trabajamos, en las jornadas, todo lo que tiene que ver con género y vida cotidiana y cómo compatibilizaban el trabajo son el mundo privado. Qué lugar tenía el trabajo en la vida de ellas, como hecho histórico, y qué lugar iba a tener de ahora en más (...) Muy interesante porque, en verdad, lo que se dio en los talleres es que las mujeres estudiaban no para un trabajo (...) Salía el "voy a hacer mecánica de moto para arreglar la moto de mi hijo, para arreglar mi moto, para mi primo" y rara vez había una mujer que te decía "yo quiero hacer esto porque me quiero ganar la vida con esto". (Coordinadora, Talleres sensibilización de género)

Como se verá a continuación, el Programa de formación se desarrolló con muchos obstáculos y resistencias. Apuntó más a generar una intervención profunda en las asistentes, orientando su 
esfuerzo a la personalización de la intervención. En este sentido, el alcance del programa fue limitado, dadas sus características de seguimiento y apuntalamiento a cada una de las cursantes. Desde una evaluación institucional, se visualizaron logros importantes, una vez que finalizó la experiencia, en las mujeres formadas por este programa, principalmente en la posibilidad de culminar la formación, revalorizar saberes previos y generar la construcción de habilidades para el trabajo. Las egresadas también señalan logros y aprendizajes (como se verá más adelante), a pesar de todas las peripecias vivenciadas en el transcurrir de los cursos. No obstante, cabe señalar que tanto a nivel de las articulaciones institucionales y de la convocatoria, como del desarrollo de los mismos cursos, la implementación del programa estuvo signada por problemas que surgieron en múltiples planos. De acuerdo a la evaluación interna del programa, el impacto efectivo de los cursos en la trayectoria laboral de las cursantes fue muy limitado y pocas jóvenes mujeres lograron insertarse inmediatamente después de los cursos en empleos afines al sector para el cual fueron formadas (a diferencia de los varones, entre quienes la inserción fue mucho menos costosa).

Yo veo como logros de este programa que las mujeres visualizaron esta propuesta como un desafío para ellas mismas, a nivel personal, pero también laboral, familiar, económico, social. En las que terminaron, vos ves que hay una mejora en su autoestima, en el reconocimiento de lo que saben y aprendieron... y con más predisposición a iniciar un proyecto propio, en donde se ve una superación personal (...) Y la oferta laboral posible luego de la realización de esta formación en mecánica no se acota al trabajo de mecánico (Directora, Coordinación de género). 


\section{Las múltiples voces de lo que implica hacer política con enfoque de género}

"Nos pusimos en irritantes... para la contraparte, para adentro del Ministerio, para afuera, para todos lados..."

Como parte de las controversias y desafíos que trajo tanto el diseño como la implementación de este programa de formación, se identifica una diversidad de voces encontradas en relación a su política de género. El diseño, la ejecución y la implementación de una política siempre suponen redefiniciones y apropiaciones, que se vinculan a las diferentes agencias y actores que deben poner en marcha acciones en el marco de una determinada coyuntura (Barbier, 1998). Las características propias de este programa suponían la interrelación de muy diferentes actores entre sí, del mundo público de la agencia gubernamental nacional y local y del mundo privado empresarial. En el diseño de la política, el enfoque de género se materializó en el hecho de garantizar un cupo de género y en el ofrecimiento de talleres de sensibilización para las mujeres cursantes y los docentes. Estos componentes, no obstante, significaron diferentes cosas para los distintos actores a la hora de llevarlos adelante.

Si por un lado el área de género del Ministerio apuntaba a sostener una política de redistribución afirmativa, la confederación empresarial, por su parte, como actor ejecutor, apostaba a otro tipo de tratamiento. Desde la visión del sector, la ocupación podía estar cubierta por mujeres. Sin embargo, no se reconocía la razón por la cual debían "favorecerlas". Para ellos, el programa debía garantizar una igualdad de oportunidades (en términos de Dubet, 2011), procurando que varones y mujeres tengan las mismas posibilidades de acceso a los cursos (destrabando posibles discriminaciones en la convocatoria y selección de cursantes). Pero luego, desde la visión del sector, había que dejar que la formación siga un curso normal, sin "sobreactuaciones" en relación al papel de las mujeres. Se buscaba promover así la lógica de la meritocracia: la formación debía ser igual para ambos y, de 
acuerdo a las capacidades personales, se accedería o no a cumplimentarlo. En este mismo sentido, evaluaban como punto erróneo que los talleres de sensibilización en género se dirijan exclusivamente a las mujeres. Si ellas recibían esos cursos (que suponían también acceder a un refrigerio, como se ve en la cita de entrevista a continuación), los varones también debían recibirlos.

Nosotros no hacemos solamente un plan de formación, lo que nosotros hacemos es un plan de empleo $y$ competitividad (...) Y con respecto a las mujeres, se anima la que le gusta el oficio, la que le gusta la moto. No se anima por ser mujer. Aquél que le gusta el oficio y piensa esto como salida laboral, sea hombre o mujer, se capacita (...) Y los talleres de género de entrada se hacían solamente con las mujeres y a propuesta nuestra se hicieron con todos los alumnos del curso. Porque si no, los seguíamos dividiendo y en realidad una política de género no es levantar a la mujer, sino promover la igualdad. Y vos promovés la igualdad cuando realmente los tratás como iguales. Me ha pasado por ejemplo con el refrigerio, yo tenía que darles a las chicas un café y una galletita y a los hombres les tenía que dar agua. Yo no puedo hacer eso, porque después los hombres me van a decir "no, muchacho, ¿cómo es esto?" (Director, confederación empresarial).

En este sentido, aparece en la voz del referente de la confederación empresarial el problema que señala Fraser (1997) en relación a las políticas de redistribución afirmativa: las acciones orientadas según este criterio, paradójicamente, exacerban la diferencia de los géneros, ubicando a las mujeres como sujetos privilegiados, avivando "las llamas del resentimiento" (Fraser, 1997:48). Así se entiende por qué, desde las voces de los instructores, la confederación y las mismas empresas del sector, se asumía que el enfoque de género estaba dado en "que no haya discriminación, que haya igualdad: es alumno, y es mecánico, sea hombre o mujer". Pero desde la voz de la Coordinación de género 
del Ministerio, esto se observó como un intento de ocupar el territorio que querían preservar para las mujeres.

Lo que pasa es que nosotros teníamos el preconcepto, y lo seguimos teniendo, de que la mujer actúa diferente cuando está un varón en el grupo a cuando están las mujeres solas. (Coordinadora, Talleres sensibilización de género)

En un sentido similar, en la convocatoria misma a los cursos, no se sostuvo con énfasis la prioridad a que se anoten mujeres. La lógica, en cambio, fue la de "esperar que lleguen mujeres interesadas", cosa que, de entrada, no ocurrió. El diseño del programa en parte subestimó la construcción de género que se evidencia no sólo en la demanda de empleo, sino también del lado de la oferta (Faur y Zamberlin, 2008). Mujeres y varones, históricamente socializados en función de la división sexual del trabajo, se ven motivados y realizan sus búsquedas laborales en concordancia con la segmentación laboral. Así, se evidenció una problemática en la convocatoria al público femenino, porque costó más de lo que se imaginó. Al mismo tiempo, las egresadas relatan, por su parte, la sorpresa de encontrarse con varones en los cursos y el hecho de que en los talleres de género también participen varones.

El proyecto dice que tiene que tener un cupo determinado, pero las mujeres no se anotaban en mecánica, quedaban haciendo bricolaje. La gente del área de género laburó muchísimo yendo a la oficina de empleo para que ipor favor lo ofrecieran! (Coordinadora, Talleres sensibilización de género)

Al principio me chocó que hubiera varones... Yo pensé que ibamos a ser todas mujeres y me dio al principio un poco de cosa... Pero igual era obvio que eso iba a pasar porque las motos es un tema de hombres (Egresada, 30 años).

Los mismos participantes varones, que conocían el enfoque de género del programa, no se mostraron sorprendidos de la dificultad en la convocatoria a las mujeres, y en el alto nivel de 
deserción entre las que finalmente se inscribieron. En las entrevistas con los egresados, el discurso compartido era el de percibir "irrazonabilidad" en la propuesta del programa en oficios no tradicionales para las mujeres. Si la ocupación de mecánico es masculina, los varones no comprenden el objetivo de formar a las mujeres en un nicho laboral sin oportunidades reales para ellas.

No me parece razonable porque no creo que consigan
nunca la cantidad de mujeres para hacer un curso. Por eso
tuvieron que hacerlo también con hombres y va a seguir
siendo así. A la mujer naturalmente no le gusta meter la
mano en la grasa, no le apasionan los fierros (Egresado, 32
años).

En el caso de los instructores -recuérdese que ellos recibieron los talleres de sensibilización en género-, la percepción sobre el enfoque del programa se encontraba asociado a "dar lugar" a la mujer en una formación típicamente masculina. Esto implicaba no sólo garantizar el acceso al curso y generar igualdad en las condiciones de aprendizaje, sino suplir conocimientos previos ausentes. Los instructores se esforzaron por animarlas y entusiasmarlas, pero también esto implicó tratarlas diferente: de acuerdo a sus visiones, a las mujeres hay que tenerles más paciencia porque desconocen el mundo de la mecánica. Hay que ayudarlas más, darles para hacer lo más sencillo, hacer "la vista gorda". El tratamiento diferenciado fue percibido por parte de las egresadas entrevistadas como un apañamiento innecesario, que demuestra la falta de confianza masculina en las propias capacidades de las mujeres.

Lo que pasa que cuando vos arrancás el curso, no es que sea más fácil con el hombre, pero generalmente el hombre ya de chiquito va conociendo... En cambio para la mujer es todo nuevo (...) Me pasó con una chica, con muchas dificultades económicas y con mucha dificultad de aprender (...) Y realmente llegó donde llegó con bastante esfuerzo mío y con un poquito de hacer la vista gorda en algunas 
cosas, comprendiendo cómo era la situación. Es decir, no le podía poner la misma exigencia que yo le pongo a otros (Instructor, Curso mecánica).

(El tema es que) que el profesor te tenga fe... Tuve que pagar bastante derecho de piso... porque a mí, al principio, me dejaban para hacer lo más sencillo. El profesor era demasiado bueno, no nos exigía tampoco, a mí me regalaba la nota, como que sentía que me tenía lástima... (Egresada, 20 años)

Desde el Ministerio se promovió que el enfoque de género no sea un mero componente (no se reduzca al cupo y a los talleres de sensibilización), sino que sea una perspectiva transversal en todas las acciones de la formación. Sin embargo, para garantizar esto, la Coordinación de género tuvo que llevar adelante una "militancia" permanente, tanto adentro del Ministerio, como en relación a la articulación con la contraparte ejecutora del Programa. La funcionaria y su equipo insistían, supervisaban y monitoreaban cada paso dado por la confederación empresarial y los instructores, reconociendo en estas acciones, una posición irritante para los otros actores. La confederación relata la insistencia del área de género y el "esfuerzo que tuvieron que hacer" para resistir una posición "exageradamente feminista".

El problema viene cuando el hombre o la mujer sobreactúa su rol. Fuimos charlando y fue mejorando, la impronta que tenía género. Tenían que dar tanto "iupi, iupi, iupi, vos podés, vos podés, vos podés, los hombres son malos" y viste... se genera algo incómodo y al principio pasó eso. Después encontramos un término medio porque la verdad que sobreactuaban lo feminista, y lo pudimos resolver... no sin pocos conflictos (Director, confederación empresarial). 
IV. Nuestro estilo es "rupturista": obstáculos, problemas y desafíos

"Habría que agarrar cabezas. Y abrir.
Trepanación de cráneos tendríamos que
hacer"

Los obstáculos encontrados en el desarrollo del programa no fueron pocos. Como hemos mencionado, la misma articulación institucional que es, en definitiva, la esencia de esta experiencia, resultó en sí misma un obstáculo. El objetivo del programa no fue interpretado por los distintos actores del mismo modo y eso repercutió, por ejemplo, en las dificultades de la convocatoria. Pero una vez iniciados los cursos, con alumnas anotadas y ya participando, las dificultades comenzaron a multiplicarse. En primer lugar, las egresadas mencionan fuertes resistencias al interior de sus hogares y en sus grupos de pares. Frases como "no me tomaban en serio", "mi familia se reía de lo que estaba haciendo", "me cargaban y me decían que iba a ser un hombre más" se repiten una y otra vez en sus relatos. En este sentido, si ya fue difícil convocar a mujeres a este tipo de formación tan particular, las resistencias encontradas en sus vínculos personales y familiares volvieron aún más difícil la decisión de sostener el curso. De todos modos, muchas mujeres tomaron estas resistencias como parte de los desafíos y trataron de demostrar que, a pesar de la desconfianza y de las cargadas, ellas podían realizarlo igual.

Y cuando lo contábamos en casa nos decían: "para qué vas a estudiar eso, si no tienen idea, qué sentido tiene". Y un poco terminamos yendo para hacerles la contra, la verdad (Egresada, 30 años).

Lo peor era afuera, gente que incluso me llegó a decir que venía acá a levantarme tipos... O está ese prejuicio de que porque hacés un curso de motos sos lesbiana... (Egresada, 20 años).

Al interior de los cursos, también comenzaron a multiplicarse los problemas. Los instructores, en algunos casos, contribuyeron 
con mayor convicción a que las alumnas mujeres se insertaran en las clases. En otros casos, esto fue más difícil: las alumnas eran dejadas de lado en el momento de la práctica. Los bancos de trabajo eran rápidamente ocupados por los varones y las chicas quedaban en el lugar de espectadoras. Las chicas debían practicar en el piso, sin la capacidad de apropiarse de las herramientas y bancos de práctica, acaparadas por sus compañeros varones. Incluso, en uno de los centros, se llegó a la decisión de que varones y mujeres juntos no podían aprender, por sus distintos niveles de conocimientos previos. Por eso, la decisión fue dividir al grupo de acuerdo al género.

En los talleres de género ellas dramatizaron estas situaciones, como por ejemplo que ellas no manejaban las herramientas pesadas, porque los varones y el profesor determinaban que eran muy pesadas. El discurso del profesor el primer día fue "acá no se viene con las uñas pintadas". No las dejaban decidir a ellas si querían meter la mano en la grasa con las manos pintadas (Coordinadora, Talleres sensibilización en género).

La representación de que la mecánica de motos no es una actividad apropiada para las mujeres "por la grasa", se reitera en las reflexiones de los varones egresados. Si bien se asume que las mujeres pueden ser más prolijas y con mayor capacidad motriz ("la mujer es mucho más detallista que el hombre, la mujer se toma más tiempo para hacer las cosas"), se comparte la visión de que es un oficio duro, con material pesado y sucio, no acorde a los principios de la feminidad. A partir de estos argumentos, se pronostica un fracaso natural del programa.

A la mayoría de las minas no les interesa la mecánica, no les gusta ensuciarse, no les gusta meterse en la grasa, no está en la naturaleza de la mujer, ¿qué querés que te diga? (Egresado, 32 años)

El de mecánica es un trabajo medio pesado para una mujer. No es una cosa fácil digamos. Para mí, yo pienso desde mi punto de vista, la mujer tiene que trabajar de otras 
cosas. La mujer puede trabajar en una oficina, tranquila, con todas las comodidades. La idea de que en el curso haya mujeres para mi va a fracasar, por el tema de que no se están orientando a una mujer que haga algo de manualidad, algo más práctico. Es algo que tiene que hacer fuerza, que tiene que andar toda engrasada. A una mujer mucho no le gusta estar sucia. Por eso, más vale que va a fracasar (Egresado, 25 años).

Esta intromisión de las mujeres en un espacio masculino trae, de acuerdo a las voces de los varones e instructores, desafíos en el plano mismo del desarrollo de los cursos. De acuerdo a sus visiones, fue "inevitable" que ante las preguntas de las mujeres, los varones larguen sus carcajadas. Un hecho de esta naturaleza ocurrió en uno de los centros cuando una alumna hizo una pregunta en donde manifestaba su desconocimiento: derivó en una risotada generalizada. Esto terminó ofendiendo a la alumna que decidió no volver. El hecho de tener que explicar "cosas obvias" a las mujeres llevó a los docentes a implementar la estrategia de designar "instructores ayudantes" (es decir, determinados alumnos, siempre varones), para que traduzcan la explicación del profesor a las chicas.

¿Se encontraron dificultades para trabajar con mujeres?

-Si, si, nos encontramos. Al principio, claro, las mujeres no sabían lo que era un destornillador, entonces tuvimos que incorporar algún nivel, $y$ eso es realmente un gran compromiso de los docentes. Por eso incorporamos el trabajo conjunto, no solamente enseña el docente, también enseña el compañero. El alumno, hombre que conoce, la mayoría conoce algo, cuando le dicen "bueno agarrá la llave 12" y la mujer no sabe qué es la llave 12, el alumno, el compañero, le dice "es esa" (Director, confederación empresarial).

Por su parte, los varones alumnos también relatan que las mujeres tienen más obstáculos que ellos para poder sostener los cursos. Como cuentan con hijos y tienen responsabilidades 
familiares, se les hace difícil mantener la asistencia. En este sentido, algunos instructores comprendieron que debían flexibilizar las reglas (incluso haciendo caso omiso a las normas establecidas por la confederación) y permitir mayores faltas o (en casos aislados) el ingreso de niños al espacio de los talleres.

A pesar de todas las dificultades con las que se desarrollaron los cursos, las mujeres entrevistadas mencionaron la importancia de la experiencia como balance general. Por un lado, visualizaron como un logro el hecho de completar un curso, que generalmente está orientado a varones ("para mí fue importante que yo, mujer, tengo un título de mecánica"). Por otro lado, plantearon como una satisfacción el haber superado sus miedos y vergüenza, y haberse inmiscuido en el territorio masculino ("es emocionante poder tocar algo que los hombres no nos dejan") y demostrar a los familiares que tienen, ahora, un saber, antes considerado de acceso imposible para ellas.

A mí me sorprendió de mí que aprendí a armar y desarmar una moto. Yo soy muy tímida, me cuesta preguntar... Pero el profesor nos explicaba tan bien que todos salimos aprendiendo... (..) El profesor también se sorprendió, nos sacamos mejores notas que ellos. (Egresada, 30 años) Me ayudó mucho, o quizás era algo que ya tenía, pero que lo reforcé: el no tener vergüenza, no tener miedo... Y también me dieron más ganas de trabajar, más ganas de dedicarme a esto. Me empezó a gustar más esto, que ya me gustaba de antes, pero ahora me gusta más (Egresada, 20 años).

Si bien en el comienzo de los cursos las mujeres sintieron la mirada "ofendida" de los varones por el lugar que ocupaban allí, en el relato de las entrevistas se menciona el diálogo fluido entablado con ellos, el compañerismo y el hecho de aprender todos juntos. La experiencia de aprendizaje mixto es valorizada por las chicas, a pesar de los temores del comienzo. (A pesar de que hay quienes asumen que "a los varones habría que darles unas charlitas de género"). En el caso de los varones, también se 
relatan aprendizajes vinculados a la experiencia de compartir el espacio con mujeres.

Algo que a mí me sorprendió es ver cómo las chicas se las ingeniaban. Porque por ahí la mujer sí carece del sentido de la fuerza, pero tiene más el sentido de buscarse la manera de lograr la fuerza. Por ahí nosotros los varones hacemos fuerza a lo bruto y llegamos a lo mismo. La mujer por ahí sabe que, adaptando una palanca, hace fuerza de palanca, y hace mucha menos fuerza y logra lo mismo (Egresado, 24 años).

De este modo, el curso se valoriza positivamente en términos de la oportunidad de acercarse a un mundo desconocido, descubrir las propias capacidades y visualizarse realizando una tarea novedosa. En algunas (pocas) egresadas, estos aprendizajes se llevan al plano concreto de una inserción laboral en el sector de actividad. Algunas mujeres entran a trabajar en una firma de moto vehículos, en una bicicletería o en un negocio de repuestos. De todos modos, el ingreso a estos empleos lejos está de realizarse sin conflictos. Las chicas relatan las dificultades que acarrea el ser mujer en un "mundo de hombres". Desde sus visiones, las mismas empresas son las que resisten el ingreso femenino a esos determinados espacios. El relato a continuación es el de una egresada que se incorporó a una firma importante de motos, en el sector de repuestos, pero fue despedida pocos meses después.

Lo que a mí me pasó, esto de que no me efectivicen, tiene que ver con que la empresa no tiene tantas ganas de contratar mujeres. Es más del lado de la empresa el problema. (...) En la empresa aprendí muchísimas cosas... Yo soy muy tímida, pero tuve que aprender a enfrentarme, a ponerme firme... Vos pensá que era la única mujer, para mí era todo un tema eso... (Egresada, 26 años)

Las dificultades llegaron hasta la misma evaluación del programa. Si bien se registraba una valoración positiva por parte 
de las alumnas mujeres, desde el punto de vista de la evaluación institucional no había forma de mostrar esta valoración. La Coordinación de género se enfrentó a la evidencia de que la lógica de actuación de una política pública está basada en poder demostrar resultados numéricos. Este programa, por sus propias características, no daba lugar a esa posibilidad: habían logrado terminar, con muchísimo esfuerzo, pocas mujeres, y muchas menos chicas habían logrado insertarse laboralmente en el sector. En este sentido, se reconoce desde la Coordinación la crítica a una lógica ministerial que no concuerda con las particularidades de llevar adelante una política de género (que debería basarse más en términos cualitativos que cuantitativos). De acuerdo a su visión, si se procura continuar con el desarrollo de políticas de esta índole, es necesario "abrir mucho más las cabezas", porque se requiere otro paradigma en relación a la efectividad y eficiencia de la política.

Te preguntaban: "¿cuántos son, cuántas son? Ay no, ¿̇eso nada más?" O sea, es muy feo, porque tenés que entrar en una lógica donde no podés mostrar el valor de estos procesos, ilas rupturas! (Directora, Coordinación de género).

\section{Reflexiones finales}

El presente trabajo tuvo como objetivo analizar la implementación de un programa de formación laboral que se propone incorporar una perspectiva de género en sus acciones. Teniendo en cuenta la persistente segmentación laboral de género que se evidencia en el mercado de trabajo, este propósito resulta relevante y pertinente.

Por un lado, la pertinencia está dada en el contexto político en el cual estas acciones se desarrollan: en los años recientes, puede evidenciarse en la Argentina un compromiso público en llevar adelante políticas orientadas a promover la equidad de género (Rodríguez, 2008), con el propósito de disminuir las brechas salariales y las discriminaciones que se imponen sistemáticamente 
a las mujeres en sus trayectorias profesionales. Este consenso puede entenderse como una consecuencia de las largas luchas del movimiento feminista, que ha logrado instaurar un discurso basado en la ampliación de los derechos y el reconocimiento de las diferencias de género en el mundo laboral. Sin embargo, como plantea Nancy Fraser (2009), el cambio indiscutible en las actitudes respecto a la desigualdad de género, no se percibe con la misma intensidad cuando se indagan las prácticas concretas. Los cuestionamientos y denuncias se multiplican en términos retóricos y se plasman en el desarrollo propuestas, objetivos y planes de acción; al mismo tiempo, las inequidades estructurales plasmadas en el mercado de empleo están lejos de verse revertidas.

Por otro lado, la relevancia de este ejercicio se reconoce en que aún no está saldado el debate en torno a lo que implica desarrollar políticas de empleo basadas en una perspectiva de género. Hay posturas que proponen la transversalización de esta perspectiva, y otras que apuestan a la intervención con grupos particulares y colectivos organizados. Asimismo, se reconocen acciones tendientes a profesionalizar y mejorar las condiciones laborales de los empleos típicamente femeninos (como puede ser el caso, en nuestro país, de las empleadas domésticas), pero también otras que apuntan a promover entre las mujeres determinadas ocupaciones cubiertas mayoritariamente por varones. Estas orientaciones se basan, a su vez, en diferentes perspectivas de justicia que se asemejan a lo señalado por Dubet (2011) y Fraser (1997); aunque generalmente es difícil reconocer la integración de las dimensiones que estos autores proponen en los diseños de las políticas. Más allá de las múltiples propuestas, puede sostenerse que integrar la dimensión de justicia en las políticas significa incorporar, desde el inicio, una perspectiva que evidencie las discriminaciones y desigualdades de género. Se trata de interrogar y leer, en las acciones aparentemente "neutras", huellas de inequidad (Rodríguez, 2008).

El programa de formación analizado muestra, principalmente, los obstáculos y las resistencias con las que se enfrenta el desarrollo de una política cuyo enfoque de género se 
orienta a romper las barreras de la segmentación laboral. Como ocurre con toda política, el plano del "diseño formal" del programa se fue reapropiando y reinterpretando en los múltiples y distintos niveles de su implementación. Estas diferentes reinterpretaciones y apropiaciones pudieron ser reconocidas en el objetivo mismo de género de la política. Si para la Coordinación desde el Ministerio se trataba de desarrollar una acción redistributiva, que suponía una discriminación positiva para las mujeres, para la confederación empresarial, se trataba de garantizar la igualdad en el acceso al programa, pero descartando lo que ellos consideraban una política "injusta" con los varones: se buscó, por el contrario, dejar que la lógica de la meritocracia determinara, en última instancia, quienes podrían cumplimentar los cursos.

Las múltiples interpretaciones respecto del objetivo de género del programa se trasladaron al desarrollo mismo de los cursos, evidenciándose problemas en todo nivel: en el modo en que debían actuar los instructores respecto de las mujeres y los varones, en la decisión de a quiénes debían estar dirigidos los talleres de sensibilización en género, en cómo debía actuarse frente a discriminaciones de parte de los mismos compañeros, en qué debía resaltarse como logro del programa, más allá de los datos vinculados a la matrícula y las tasas de egreso. En cada una de las situaciones analizadas se evidencian fuertes resistencias $e$ incomodidades a la propuesta de integrar mujeres en un territorio considerado masculino.

En este sentido, Fraser (2008), de acuerdo a una concepción compleja de la equidad de género que incluye diferentes normas que deben ser respetadas simultáneamente, sostiene que toda política con esta orientación requiere del cuestionamiento y la modificación de las normas de género existentes en la sociedad. Esto es necesario no solamente para los empleos típicamente masculinos, sino también para todos los empleos que, contemporáneamente, exigen de los trabajadores/as el perfil de un individuo libre, sin trabas, automodelado, proactivo y fiel al trabajo en tiempo completo. Ese tipo de individuo imaginado, es 
siempre un trabajador varón. Entonces, no alcanza con asegurar que las mujeres se integren y adapten a instituciones asociadas al mundo masculino. Hacer sólo eso puede correr el riesgo de reafirmar la desvalorización del colectivo femenino en dichos espacios, sin cuestionar y transformar las normas machistas presentes en esas instituciones.

Los obstáculos y resistencias analizadas invitan a retomar las discusiones teóricas sobre la complejidad de la organización del género, que no debe comprenderse como un mero dato clasificatorio (varón/mujer), sino como una matriz de inteligibilidad que organiza nuestras prácticas y representaciones. Como plantea Butler (2005), si bien las identidades generizadas son producidas por las prácticas reguladoras de una matriz de la coherencia de género, al mismo tiempo, se construyen performativamente. El género es siempre un hacer $\mathrm{y}$, de este modo, la matriz de inteligibilidad se sostiene gracias a su poder reiterativo. Butler propone que las identidades que no se ajustan a esas normas reguladoras de la matriz de inteligibilidad (es decir, que no se ajustan a la "gramática de género"), en su insistencia y proliferación, terminan mostrando los límites mismos de ese campo de legitimidad, y proponen posiciones diferentes $y$ subversivas que colaboran en su desorden.

Si pensamos en el caso analizado, puede pensarse que un programa que promueve la formación e inserción laboral de mujeres en oficios del mundo masculino actúa, precisamente, en un plano estructural de la organización de género, que si bien puede "reavivar las llamas del resentimiento", también puede contribuir a "desordenarlas", subvertirlas y cuestionarlas. Pero justamente por eso mismo, las resistencias con las que se encontrará no serán pocas ni fáciles de sortear. El artículo ha intentado mostrar la enorme dificultad que acarrea llevar adelante una política con estas características, que requiere de permanentes ajustes en función del contexto particular de implementación y de las características de los actores involucrados en la puesta en marcha. Al mismo tiempo, cada una de esas resistencias puede ser pensada como el indicador de que efectivamente se trata de una 
intervención disruptiva, cuyo potencial es la generación de prácticas de desorden de las estructuras normativas del género. En este sentido, desde las voces de las participantes y actores implicados, el artículo muestra que el programa produce reflexiones y transformaciones subjetivas que invitan a asumir que vale la pena dar la batalla.

\section{Referencias bibliográficas}

BATES, I. Closely Observed Training: an exploration of links between social structures, training and identity. International Studies in Sociology of Education, vol. 1, n 1-2, 1991, pp.225-243.

BARBIER, J. Analizar la implementación: una herramienta indispensable para la evaluación de las políticas públicas de empleo. In: GAUTIÉ, J.; NefFA, J. (comps). Desempleo y Politicas de Empleo en Europa y Estados Unidos. Buenos Aires, Ed. Asociación Trabajo y Sociedad, 1998, pp.373-387.

BUtLER, J. Cuerpos que importan. Sobre los límites materiales y discursivos del "sexo". Buenos Aires, Paidós, 2005.

CEMYT. Situación laboral de las mujeres período 2009-2010. Informe ${ }^{\circ}$ 3, Buenos Aires, CTA, 2011.

DUBET, F. Repensar la justicia social. Contra el mito de la igualdad de oportunidades. Buenos Aires, Siglo XXI, 2011.

FAUR, L.; ZAMBERLIN, N. Gramáticas de género en el mundo laboral. Perspectivas de trabajadoras y trabajadores en cuatro ramas del sector productivo del área metropolitana de Buenos Aires. In: Novick, M.; ROJO, S.; CASTILLO, V. (comps). El trabajo femenino en la postconvertibilidad 2003-2007. Buenos Aires, CEPAL GTZ, MTEySS, 2008, pp.85-117.

FigARI, C.; SPINOSA, M.; TeSTA, J. (comps). Trabajo y formación en debate. Saberes, itinerarios y trayectorias de profesionalización. Buenos Aires, CICCUS, 2011.

FORMUJER. Un modelo de política de formación para el mejoramiento de la empleabilidad y la equidad de género: El Programa Formujer. Montevideo, Cinterfor, OIT, 2004. 
FRASER, N. Iustitia Interrupta. Reflexiones críticas desde la posición postsocialista. Santa Fe de Bogotá, Siglo del Hombre Editores, Universidad de los Andes, 1997.

FRASER, N. La justicia social en la era de la política de identidad: redistribución, reconocimiento y participación. Revista de Trabajo, año 4, n 6, MTEySS, 2008, pp.83-99.

FRASER, N. El feminismo, el capitalismo y la astucia de la historia. New Left Review, n 56, may/june, 2009, pp.87-104.

JaCinTo, C.; Gallart, M. A. (coords). Por una segunda oportunidad. La formación para el trabajo de jóvenes vulnerables. Montevideo, CINTERFOR-RET, 1998.

JACINTO, C.; MiLlENAAR, V. Educación, capacitación y transiciones laborales. ¿Rupturas provisorias en las trayectorias de los jóvenes provenientes de hogares de bajo capital educativo? Revista Sudamérica, $\mathrm{n}^{\circ}$ 2, Universidad Nacional de Mar del Plata, 2013, pp.63-90.

LEÓN, F. Mujeres y discurso pedagógico en la escuela técnica. In: VILLA, A. (coord.) Sexualidad, relaciones de género y de generación. Perspectivas histórico-culturales en educación. Buenos Aires, Noveduc, 2009, pp.171-211.

MAURIZIO, R. Enfoque de género en las instituciones laborales y las políticas del mercado de trabajo en América Latina. Serie Macroeconomía del Desarrollo, n 104, Santiago de Chile, CEPAL, 2010.

MILLENAAR, $\mathrm{V}$. Trayectorias de inserción laboral de mujeres jóvenes pobres: el lugar de los programas de Formación Profesional y sus abordajes de género. Revista Trabajo y Sociedad, $\mathrm{n}^{\circ} 22$, vol. XVII, Universidad Nacional de Santiago del Estero, 2014, pp.325-339.

MillenAAR, V.; JACINTO, C. Desigualdad social y género en las trayectorias laborales de jóvenes de sectores populares. El lugar de los dispositivos de inserción. In: MAYER, L.; LLANOS, D.; UNDA LARA, R. (comps). Socialización escolar. Procesos, experiencias y trayectos. Ecuador, Abya Ayala, Universidad Politécnica Salesiana, CINDE y CLACSO, 2015, pp.73-100. 
Morgade, G.; KAPLAN, C. Mujeres esmeradas y varones inteligentes: juicios escolares desde un enfoque de género. Revista Argentina de Educación, Buenos Aires, n²6, AGCE, 1999, pp.67-78.

NovicK, M.; Rojo, S.; CASTILlo, V. (comps). El trabajo femenino en la post-convertibilidad 2003-2007. Buenos Aires, CEPAL GTZ, MTEySS, 2008.

OIT. Trabajo decente e igualdad de género. Políticas para mejorar el acceso y la calidad del empleo de las mujeres en América Latina y el Caribe. CEPAL, ONU, PNUD y OIT, 2013.

RodRíGuez, M. J. Políticas públicas que contribuyan a la equidad de género: reconocer el problema para decidir cómo abordarlo. Revista de Trabajo, año 4, n 6, MTEySS, 2008, pp.71-81.

RoJo, S.; TUMINI, L. Inequidades de género en el mercado de trabajo de la Argentina: las brechas salariales. Revista de Trabajo, año 4, $n^{\circ} 6$, MTEySS, 2008, pp.53-70.

SEGATO, R. L. Las estructuras elementales de la violencia. Ensayos sobre género entre la antropología, el psicoanálisis y los derechos humanos. Buenos Aires, Prometeo, UNQui, 2003.

SILVEIRA, S. La dimensión de género y sus implicaciones en la relación entre juventud, trabajo y formación. In: PIECK, E. (coord). Los jóvenes y el trabajo: la educación frente a la exclusión social. México, UIA, IML, UNICEF, CINTERFOR, OIT, RET y CONALEP, 2008, pp.457491.

SkEGGS, B. Formations of Class and Gender. Londres, Sage, 1997.

SuBIRATS, M. Género y escuela. In: LOMAS, C. (comp). ¿Iguales o diferentes? Género, diferencia sexual, lenguaje y educación. Barcelona, Paidós, 1999, pp.19-32.

YANNOULAS, S. Perspectivas de género y políticas de formación e inserción laboral en América Latina. Buenos Aires, IDES-IIPE/Red ETIS, 2005.

YANNOULAS, S. (coord). Trabalhadoras. Análise da feminização das profissões e ocupações. Brasilia, Abaré Editorial, 2013. 